\title{
Aneurysmal cyst of the petrosal bone
}

\author{
G-M Lackmann, U Töllner
}

\begin{abstract}
An aneurysmal cyst of the petrosal bone presenting as hearing loss and recurrent bacterial meningitis is reported. None of the clinical or radiographic signs described previously were present. Because other diagnostic methods are not reliable, it is recommended that coronal thin section computed tomography be performed in every case of suspected malformation of the skull base and in the diagnosis of recurrent bacterial meningitis.

(Arch Dis Child 1993; 69: 241-242)
\end{abstract}

Aneurysmal bone cysts, as originally described in 1942 by Jaffe and Lichtenstein, ${ }^{1}$ are benign osteolytic lesions consisting of an intraosseous, destructive tumour and an extraosseous, aneurysm-like cyst. They are seen mainly in vertebrae and flat bones, but can also arise in the shaft of long bones. The majority of such lesions grow as externally visible lumps, often tender to palpation, and come to medical attention during adolescence (mean age, 14.5 years). ${ }^{2}$ Involvement of facial and calvarial bones is rare. A search of the literature revealed 45 case reports. Only in three patients were the skull base and the basal sinuses involved. ${ }^{4-6}$

This case report is unique in that firstly a presumably congenital aneurysmal bone cyst of the petrosal bone is described; secondly the lesion initially presented with signs of an occult dysplasia of the skull base, that is hearing loss and recurrent bacterial meningitis.

\section{Case report}

The boy was the second child of healthy parents. Pregnancy and labour were normal. After an initially normal neurological development there was considerable speech delay. At the age of 4 years he suffered meningococcal meningitis. Ear, nose, and throat examination revealed a right sided labyrinthine hearing loss which was attributed to meningitis. At the age of 6.8 years the boy fell ill with streptococcal meningitis. Suspecting a cerebrospinal fluid fistula, we obtained a cranial computed tomogram; this showed dilatation of the lateral ventricles and basal cisterns without evidence of intracranial mass effect or intracerebral haemorrhage. Coronal thin section computed tomography of the skull base showed a space occupying lesion extending over the right tympanum, epitympanum, and antrum with destruction of the auditory ossicles and the osseous lamella to the middle cranial cavity, as well as shadowing of the right mastoid bone. Microscopic evaluation of the biopsy material showed typical histological findings of an aneurysmal bone cyst.
At operation, after craniotomy and transtemporal covering of the basal defect, the cystic lesion was resected in toto in the region of the Fallopian canal and the tympanic cavity. At the same time, the facial nerve had to be removed because of an opened internal auditory meatus and macroscopic destruction. The resulting facial nerve palsy led to a second operation, at which an intracranialtranstemporal anastomosis of the nerve was planned. Because of possible retraction of the nerve stump to the cerebellopontine angle, the operation was again performed as a combined neuro-otosurgical procedure. The patient made a remarkable recovery and was discharged from hospital four weeks later.

\section{Discussion}

Aneurysmal bone cysts are normally seen in the bones of the spine and flat bones, occurring in the second decade of life. ${ }^{23}$ Involvement of the facial and calvarial bones is rare, and localisation at the skull base has been described previously in only three cases. ${ }^{4-6}$ Nothing is known about the pathogenesis of this tumour. ${ }^{2}$ Jaffe originally proposed that the lesion might be produced by a haemorrhagic 'blow out' of a pre-existing lesion. ${ }^{1}$ If the blow out occurs within the calvarium or long bones, the typical 'soap bubble' appearance would be produced. However, if a blow out occurs within brain parenchyma, it may produce an intracranial haemorrhage. As such an event has been described only once in the literature, ${ }^{3}$ we suggest that other aetiological factors must be considered. Some authors suggest preceding trauma to the bone, although there is not usually evidence of any injury. ${ }^{2}$ Congenital or acquired lesions of intraosseous vessel walls, leading to local ischaemia and growth disturbance of the bone, may be additional factors. ${ }^{12}$ In the light of the case reported in this paper, two aetiological explanations are possible:

(1) Our patient suffered a (so far undescribed) congenital aneurysmal bone cyst that led to congenital labyrinthine hearing loss. Later, a cerebrospinal fluid fistula with recurrent bacterial meningitis complicated the initial bony lesion. This hypothesis is corroborated by the fact that the boy exhibited delayed speech development long before the first clinical sign (bacterial meningitis) of a destructive skull base lesion. Moreover, it coincides with the observations of other authors that the growth of aneurysmal bone cysts may be very slow. ${ }^{2}$ These considerations would support the theory of a congenital lesion possibly affecting intraosseous vessels. ${ }^{12}$

(2) The failure of speech development in our patient was independent of the aneurysmal

\author{
requests to: \\ für Kinder- und \\ Jugendmedizin, Städtisches \\ Klinikum Fulda, Pacelliallee \\ 4, 6400 Fulda, Federal \\ Accepted 14 April 1993 \\ Paediatrics, \\ Fulda, Teaching \\ Marburg, Federal \\ Republic of Germany
}


bone cyst, and both hearing loss and aneurysmal bone cyst were results of the initial bacterial meningitis. The association between bacterial meningitis and hearing loss is well known. Bacterial infection as an aetiological factor in the development of an aneurysmal bone cyst may be due to an accompanying vasculitis resulting in local ischaemia and growth disturbance of the bone as mentioned above. Proof of whether either of our theories are true awaits further observations.

Even if the diagnosis of an aneurysmal bone cyst can be made by radiography, this diagnostic method is not reliable. 'Typical' signs on radiography have been described by several authors, ${ }^{23}$ for example soap bubble or blow out appearance (see above), eggshell type calcification, or lytic skull lesions, but the morphological changes vary considerably from patient to patient. ${ }^{23}$ Moreover, in cases of skull base cysts, plain radiographs of the skull and even axial computed tomograms are of little diagnostic value. Only coronal thin section computed tomograms will provide diagnostic clues, as shown in our patient. We therefore recommend performing these scans in every case of suspected malformation of the skull base and in the diagnosis of aetiologically obscure recurrent bacterial meningitis. ${ }^{7}$

Because of the possible coincidence with malignant tumours, ${ }^{2}$ destructive growth of the lesion per se, and the high recurrence rate of nearly $21 \%,{ }^{3}$ total surgical dissection of the cyst should be the primary therapeutic goal.

We thank surgeons Professor Dr W Draf, head of the department of ear, nose, and throat, head, neck, and facial reconstructive surgery, Fulda, and Professor Dr H P Richter, then head of the department of neurosurgery, Fulda.

1 Jaffe HL, Lichtenstein L. Solitary unicameral bone cyst: with emphasis on the roentgen picture, the pathologic appearance, and the pathogenesis. Arch Surg 1942; 44: 1004-25.

2 Wachter W, Adler CP. Aneurysmale Knochenzyste des Os temporale. Laryngorhinootologie 1984; 63: 622-5.

3 Keuskamp PA, Horoupian DS, Fein JM. Aneurysmal bone cyst of the temporal bone presenting as a spontaneous intracerebral hemorrhage: case report. Neurosurgery 1980; intracerebral

4 Delorit GJ, Summers GW. Aneurysmal bone cyst of the sphenoid sinus. Transactions of American Academy of Ophthalmology and Otolaryngology 1975; 80: 438-43.

5 Revuelta M, Jos VL, Trujillo F, Albert P. Dos casos raros de tumor de la base del craneo: osteoclastoma y quiste oseo aneurismatico. Revista Espanola Oto-Neuro-Oftalmologia Y Neurocirugia 1975; 33: 19-23.

6 Yee RD, Cogan DG, Thorp TR, Schut L. Optic nerve compression due to aneurysmal bone cyst. Arch Ophthalmol 1977; 95: 2176-9.

7 Draf W. Malformations of the skull base. In: Pfeifer G, ed. Craniofacial abnormalities and clefts of the lip, alveolus and palate. Stuttgart: Thieme, 1991: 40-3.

\title{
Hepatic abscess in sickle cell anaemia: a rare manifestation
}

\author{
Meera Lama
}

\begin{abstract}
A child with sickle cell anaemia developed a hepatic abscess, which was managed successfully by percutaneous drainage under ultrasound control. A history of attacks of pain dissimilar to usual vasoocclusive crises should be treated with suspicion and investigated appropriately. (Arch Dis Child 1993; 69: 242-243)
\end{abstract}

Hepatic abscess as a complication of sickle cell anaemia has been described only once before in childhood. ${ }^{1}$ The first case managed successfully by percutaneous drainage guided by ultrasound is reported here.

\section{Case report}

Department of Paediatrics, National Guard King Khalid Hospital, Jeddah Saudi Arabia

Correspondence to: Dr Meera Lama, Department of Paediatrics, East Birmingham Hospital, Bordesley Green East, Birmingham B9 5SS.

Accepted 29 April 1993
A 10 year old Saudi girl, known to have sickle cell anaemia, presented to the casualty department with a one month history of recurrent right abdominal pain and intermittent fever. She had been seen repeatedly during this time and was thought to be suffering from mild abdominal vaso-occlusive crises and sent home on analgesics, with little response.

The casualty officer had considered the child was probably using the pain as an excuse for missing school. Interestingly though, this was the child's first presentation with abdominal pain and she was emphatic that it was totally dissimilar to any previous vaso-occlusive episodes.

On examination she looked unwell and was feverish $\left(39^{\circ} \mathrm{C}\right)$, in severe abdominal pain, and pale with a tinge of jaundice. Abdominal examination revealed tender hepatomegaly ( $5 \mathrm{~cm}$ below the costal margin in the midclavicular line).

Initial investigations included a haemoglobin concentration of $62 \mathrm{~g} / \mathrm{l}$, a raised white cell count $\left(27 \cdot 3 \times 10^{9} / 1\right)$, mainly neutrophils with a left shift, and a platelet count of $927 \times 10^{9} / 1$. Blood urea and electrolyte concentrations were within normal limits. Chest and upper abdominal $x$ ray films showed abnormal elevation of the right cupola of the diaphragm with some right basal reaction (fig 1). Abdominal ultrasound confirmed the presence of an abscess in the right lobe of the liver showing as two hypoechoic areas containing some necrotic elements, lying approximately $8.5 \mathrm{~cm}$ from the surface (fig 2 ).

\section{MANAGEMENT}

The child was commenced on intravenous fluids, analgesics, and broad spectrum anti- 